\title{
De la crisis estructural del patrón de poder mundial, colonial, moderno y capitalista hacia la solidaridad económica y los buenos vivires en América Latina
}

Boris Marañón*

Doctor en Estudios Latinoamericanos. Investigador del Instituto de Investigaciones Económicas, Universidad Nacional Autónoma de México (UnAM), México.

Correo electrónico

maranonboris@gmail.com

Recibido: 17 de enero del 2016

Aceptado: 31 de mayo del 2016

Cómo citar este artículo: Marañón, B.

(2016). De la crisis estructural del patrón de poder mundial, colonial, moderno y capitalista hacia la solidaridad económica y los buenos vivires en América Latina. Cooperativismo \& Desarrollo, 24(109), xx-xx. doi: 10.16925/ co.v24i109.1500

\section{Resumen}

Propósito: el presente artículo busca orientar pensamientos y prácticas solidarias desde una perspectiva que trascienda lo económico y lo ético. Descripción: se incluyen, no solo las relaciones de poder que sustentan la vida en la sociedad capitalista, sino también la necesidad de tomar consciencia de que estamos ante un dramático cambio de "época", ya que tanto los proyectos del progreso-desarrollo como el de la modernidad atraviesan crisis irreversibles, y lo que debemos cuidar es la vida. Punto de vista: en este sentido, se plantea el concepto de solidaridad económica, que permite, asumiendo una diversidad económica y cultural, vincular todas las prácticas inspiradas en racionalidades liberadoras y solidarias, más allá de la adscripción que puedan tener a determinadas corrientes éticas, políticas y culturales o a específicas formas institucionales; estas se basan en la reciprocidad, la desmercantilización y el autogobierno, y están asociadas con un nuevo horizonte: el buen vivir o los buenos vivires orientados hacia la decolonialidad. Conclusiones: se debe advertir que la lucha por una sociedad alternativa no solo es una lucha económica y ética, sino que la crisis estructural actual abarca a toda una forma histórica de convivencia humana, a todo el conjunto del patrón de poder colonial-moderno y capitalista.

Palabras clave: buenos vivires, decolonialidad del poder, solidaridad económica. 


\title{
From the structural crisis of the pattern of world, colonial, modern, and capitalist power toward economic solidarity and good living in Latin America
}

\begin{abstract}
Purpose: This article seeks to guide solidarity thinking and practices from a perspective that transcends economic and ethical concerns. Description: Included are not only the power relations that sustain life in capitalist society, but also the need for awareness that we are facing a dramatic epoch shift. Both the progress/ development and modernity projects are undergoing irreversible crises, and we must prioritize taking care of life. Viewpoint: To this end, the concept of economic solidarity is put forward, which allows-assuming economic and cultural diversity-the linking of all practices inspired by liberating and solidarity rationales. Going beyond their possible assignment to certain ethical, political, and cultural schools of thought or to specific institutional forms, these rationales are based on reciprocity, decommodification, and self-government. They are also associated with a new horizon: good living, or, good livings oriented toward decoloniality. Conclusions: It should be noted that the struggle for an alternative society is not only an economic and ethical struggle; the current structural crisis encompasses an entire historical form of human coexistence and the whole pattern of colonial-modern and capitalist power.
\end{abstract}

Keywords: good living, decoloniality of power, economic solidarity

\section{Da crise estrutural do padrão de poder mundial, colonial, moderno e capitalista para a solidariedade econômica e os bons viveres na América Latina}

\section{Resumo}

Propósito: o presente artigo procura orientar pensamentos e práticas solidárias a partir de uma perspectiva que transcenda o econômico e o ético. Descrição: incluem-se, não só as relações de poder que sustentam a vida na sociedade capitalista, mas também a necessidade de tomar consciência de que estamos diante de uma dramática mudança de "época", já que tanto os projetos do progresso-desenvolvimento quanto o da modernidade atravessam crises irreversíveis, e o que devemos cuidar é a vida. Ponto de vista: nesse sentido, propõe-se o conceito de solidariedade econômica, que permite, assumindo uma diversidade econômica e cultural, vincular todas as práticas inspiradas em racionalidades liberadoras e solidárias, para além da afiliação que possam ter a determinadas correntes éticas, políticas e culturais ou a específicas formas institucionais; estas se baseiam na reciprocidade, na desmercantilização e no autogoverno, e estão associadas com um novo horizonte: o bom viver ou os bons viveres orientados para a decolonialidade. Conclusões: deve-se advertir que a luta por uma sociedade alternativa não é apenas uma luta econômica e ética, mas também que a crise estrutural atual abrange toda uma forma histórica de convivência humana e todo o conjunto do padrão de poder colonial-moderno e capitalista.

Palavras-chave: bons viveres, decolonialidade do poder, solidariedade econômica. 


\section{Introducción ${ }^{1}$}

En las últimas décadas se ha registrado en América Latina una expansión muy importante de las prácticas económicas solidarias en diversas formas asociativas, cubriendo una amplia gama de actividades que tienen como base la reciprocidad y el autogobierno o comunidad. Estas prácticas reciben diversas denominaciones, en las que destacan las de "economía popular de solidaridad", "economía del trabajo", "economía solidaria" y "economía social y solidaria"; estas han inspirado estudios teóricos y empíricos importantes por parte de destacados investigadores latinoamericanos ${ }^{2}$, que han contribuido a darles tanto visibilidad como legitimidad social y política. Estas prácticas han surgido y se han expandido en una época en que, por la influencia del subjetivismo, preocuparse por "el otro" o la "otra", y tratar de resolver los problemas básicos de la existencia social de manera colectiva no solo es irracional, sino arcaico. No obstante, tales reflexiones están impregnadas de una aceptación de la visión dominante que naturaliza el poder, sus prácticas e instituciones; de su imaginario, el del progreso-desarrollo, y del proyecto de la modernidad, pues no se ha advertido de manera suficiente que están en crisis las bases epistemológicas de la producción de saberes científicos, porque estos pueden explicar la realidad social solo parcial y distorsionadamente.

El artículo está estructurado en cuatro partes. La primera despliega una crítica al eurocentrismo, a la forma de conocimiento hegemónico; la segunda presenta herramientas que permiten ubicar las prácticas solidarias en la sociedad capitalista mundial, caracterizando el periodo histórico actual como uno de crisis estructural e irreversible del patrón de poder colonial, moderno, capitalista, mundial y del progreso-desarrollo. La tercera plantea considerar a la solidaridad económica, que está vinculada con el buen vivir, como un concepto que incluye todas las prácticas solidarias, más allá de adscripciones específicas y de su reconocimiento legal. Estas prácticas solidarias tienen como enemigo común al capital y al capitalismo, y tratan de dejar atrás el imaginario del "proyecto civilizatorio occidental"; esto a partir

Este artículo se enmarca en la investigación del proyecto DGAPA-PAPIIT IN303216, UNAM, "De la crisis estructural del empleo al trabajo recíproco en el México actual. Discursos y prácticas en organizaciones económicas solidarias".

Veánse Razeto (1998, 2011 y 2013), Coraggio (2001, 2004, 2008 y 2015) y Singer (2002, 2007 y 2009). de racionalidades liberadoras y solidarias. Se discute, además, si la solidaridad debe ser impulsada como un conjunto subordinado de relaciones sociales no capitalistas dentro del proyecto del progreso-desarrollo capitalista o es necesario impulsarlas como parte de otro horizonte histórico de sentido, el buen vivir, que se ubica en ruptura con el proyecto de la modernidad. Finalmente, se plantean algunas reflexiones.

Es necesario alejarse de la visión dominante en el estudio de lo solidario, pues la producción de conocimiento científico es parte de las relaciones de poder y, por tanto, no existe una verdad neutra, objetiva, sino una según la cual los intereses sociales de sectores específicos son universales y legítimos (Wallerstein, 1996; 1998). Este desplazamiento debería ser epistemológico y ontológico, de manera que se cuestione la estructura del saber dominante y poner en duda nuestras creencias, teorías, categorías e imágenes que fundamentan nuestras prácticas; así, se cuestionan las narrativas del progreso-desarrollo y de la modernidad, y se buscan nuevas preguntas y respuestas sobre la realidad social, la solidaridad y la economía.

Partimos de la descolonialidad del poder (CP), que rompe con el eurocentrismo y analiza el poder en la modernidad; esto devela la colonialidad como la cara oculta de la modernidad, ya que desde la conquista de América se estableció como la primera patrona del poder mundial, moderno/colonial y capitalista. Se denomina mundial, porque abarcó a toda la población del mundo; moderno, debido a que se impuso el proyecto de la modernidad europea caracterizado por la razón instrumental de medios afines, basada en el avance científico-tecnológico y orientada a la acumulación de capital, y colonial, dado que legitimó las relaciones de dominación y explotación de los conquistadores sobre los conquistados a partir del criterio de "raza"; estas relaciones se han mantenido hasta la actualidad a pesar de los procesos independentistas.

En la CP la cuestión del poder es central. Este es entendido como una relación social constituida por tres elementos: dominación, explotación y conflicto ${ }^{3}$; a su vez, este articula los ámbitos básicos de la existencia social, como el del trabajo, la autoridad colectiva, la intersubjetividad, el sexo y la naturaleza ${ }^{4}$ (Quijano, 2007a).

$3 \quad$ El conflicto alude a la disputa permanente por el control de los ámbitos mencionados.

4 Para ver cómo opera la colonialidad en cada uno de los ámbitos de existencia y se perfila la descolonialidad desde la solidaridad económica, veánse Marañón (2012a) y Marañón a (en prensa). 
Este patrón de poder se originó a través de un doble movimiento. En primer lugar hubo un desplazamiento hacia la modernidad, en el cual se buscaba instituir la convivencia social a partir de la igualdad, la autonomía individual y la solidaridad, mirando al futuro. En segundo lugar, existe un direccionamiento hacia la colonialidad: a partir de la idea de raza ${ }^{5}$, se jerarquizan y legitiman relaciones de dominación de los "blancos" sobre los "no blancos". Esta colonialidad se impone con las instituciones básicas de mercado/empresa/trabajo asalariado, de Estado/ciudadanía, de conocimiento científico racionalista-positivista, de una familia patriarcal y de dominio de la naturaleza a través de la ciencia y la tecnología.

La palabra descolonialidad hace referencia a las luchas y prácticas sociales orientadas a desmantelar la dominación y la explotación propias del patrón de poder actual, de modo que se extienda la reciprocidad entre individuos, que contribuya a la desmercantilización del trabajo y la vida, que se abran espacios para el autogobierno, que a partir de la interculturalidad se diluyan las jerarquías entre saberes científicos y no científicos, que se establezca una igualdad y complementariedad entre los géneros $y$, finalmente, que la relación con la Madre Tierra, nuestra casa común, sea también de reciprocidad. En el ámbito de la intersubjetividad, la deconstrucción del discurso dominante de una modernidad asociada a la razón instrumental y al capitalismo, que tiene al progreso-desarrollo como un punto de llegada de todo el mundo según los logros alcanzados por Europa y Estados Unidos, representa un esfuerzo en ese sentido.

\section{La crítica decolonial al eurocentrismo}

El eurocentrismo se basa en tres elementos. Primero, está la simplificación, propuesta cartesiana de dividir lo complejo en partes simples para estudiarlas de manera aislada. Esta lleva a la compartimentalización del saber, a la especialización del conocimiento,

La clase y el género son otros criterios, pero Quijano sostiene que el de clase no resulta tan abarcador porque alude solo a la ubicación de las personas en el ámbito del trabajo - ahí donde logró extenderse la relación capital/salario principalmente Europa y Estados Unidos-, en tanto que el de género antecede al actual patrón de poder ya que las relaciones de dominación patriarcales existen antes del patrón de poder moderno/colonial. María Lugones (2012) ha propuesto la categoría de interseccionalidad para dar cuenta de los tres criterios de clasificación social, principalmente raza y género, y revelar lo que no se ve cuando estos son considerados por separado. al surgimiento de una comprensión de las disciplinas como categorías intelectuales con su objeto y método de estudio específico, y como categorías institucionales, al convertirse en departamentos que constituyen la base organizativa de las universidades "modernas". Segundo, se encuentra la estabilidad de los sistemas sociales y naturales a partir de leyes simples, que son posibles de conocer, lo que permite prever lo que va a ocurrir y, por lo tanto, controlar o moldear tanto el mundo natural como el mundo social. Esta creencia lleva al determinismo y a la irreversibilidad; esto es, la eliminación de la historia como proceso creativo. Por último, se tiene la objetividad, según la cual se puede conocer la realidad tal como es, poniendo entre paréntesis al sujeto, lo que supone la aceptación de un conocimiento libre de valores (Germaná, 2014)

El eurocentrismo se construyó, históricamente, a partir de una visión colonial de la experiencia social mundial, es decir, desde la "invención" en el siglo xvi de la "raza" como un constructo social y la negación epistemológica y ontológica de los "no europeos" por parte de los "europeos"; a los no europeos se les considera inferiores cultural y biológicamente (Quijano, 1992). En este punto es crucial la propuesta de Lander (2000) sobre el sujeto, pues, según él, este no es alguien en abstracto que expresa una verdad universal y objetiva despojada de valores e intereses sociales, sino de un hombre "blanco", burgués, patriarcal, propietario y, por lo menos en lo público, heterosexual, que expresa una racionalidad colonial-moderna. En este sentido, es indispensable precisar el lugar de enunciación del sujeto para hacer evidente el dispositivo epistemológico que lo invisibiliza en términos sociales, históricos y, en definitiva, del patrón de poder colonial-moderno, como propone Lander (2000). El eurocentrismo ha sido impuesto como la única racionalidad legítima y como una justificación de la dominación y destrucción de otras formas de saber y de vida, las no europeas o no blancas, colonizando el imaginario de los dominados, los mismos que se sienten inferiores, aspiran a imitar los modos de vida de los dominadores y reproducen sus formas de producción de conocimiento (Quijano, 1992).

Desde la perspectiva de la $\mathrm{CP}^{7}$, se cuestionan los fundamentos del saber hegemónico en el sistema moderno, colonial y capitalista, entre estos, que

\footnotetext{
$6 \quad$ Sobre este punto, ver De Sousa Santos (2009) y Germaná (2002).

$7 \quad \mathrm{Al}$ respecto ver la antología de Quijano a cargo de Danilo Assis Clímaco, Quijano (2014a) y el blog anibalquijano.blogspot.mx
} 
se considere al Estado-nación como unidad de análisis; que la dominación y explotación estén basadas en relaciones de clase (definidas por la propiedad de los medios de producción); que la epistemología sea una de simplificación; que hay una separación entre sujeto y objeto, $y$, finalmente, que haya una separación entre las formas de conocimiento.

Frente a esta manera distorsionada de entender la realidad, la CP plantea que la unidad de análisis es el patrón de poder mundial moderno y colonial impuesto desde el siglo xvi con la conquista europea de lo que se denominaría América y que las relaciones de dominación y explotación no están basadas solamente en lo económico-político (relaciones sociales de producción-control del Estado), sino que tienen un fundamento simbólico que las legitima a partir de la idea de raza, de lo que se desprende la racialización de las relaciones de poder inherente al patrón de poder vigente. A su vez, la CP critica la separación entre lo político, lo económico, lo social y lo cultural, y, también, la especialización disciplinaria del conocimiento social. Estos procesos son analizados por Wallerstein (1996 y 1998), quien propone una especialización no disciplinaria, sino por problemáticas específicas o campos de investigación. Así, la CP propone un análisis desde la totalidad social, es decir, desde los distintos ámbitos y momentos de la existencia social (autoridad pública, trabajo, subjetividad, género, "naturaleza"), entre los cuales se establece una malla de relaciones que se expresan en relaciones de poder (dominación-explotación y conflicto). En esta teoría, se rechaza la distinción entre sujeto y objeto del conocimiento; igualmente, toma distancia tanto del objetivismo como del subjetivismo: ambos limitan el conocimiento de la realidad social, ya que si bien existe un mundo independiente del sujeto, este interviene en la producción del conocimiento, pues, al medir, se modifica lo medido. El conocimiento aparece, en consecuencia, como un producto intersubjetivo: hace parte de las estructuras intersubjetivas y las reglas epistemológicas que establecen la verdad son reglas sociales. En último lugar, esta teoría cuestiona la separación entre el conocimiento científico y el conocimiento humanístico, proponiendo la conjunción de ambos con el objetivo de hallar explicaciones que tengan en cuenta lo bello, lo verdadero y lo justo (Germaná, 2014) ${ }^{8}$.
La crítica al eurocentrismo permite, pues, tener elementos para develar cuáles son los fundamentos epistemológicos de la ciencias sociales dominantes y reflexionar de otra manera respecto de la solidaridad económica. Los fundamentos son separación sujeto/ objeto, simplificación, objetividad, estabilidad, separación de las formas de conocimiento. Al verlos se puede entender por qué este conocimiento conduce a explicaciones parciales y distorsionadas de la realidad, desde el punto de vista de los dominados y explotados por este patrón de poder.

La crítica descolonial propone realizar el análisis de las relaciones sociales a partir de relaciones sujeto-sujeto. La racionalidad hasta ahora dominante, elaborada por Europa, ha excluido en términos epistemológicos y ontológicos a la "no Europa", a todos aquellos "no blancos", por su supuesta inferioridad de raza, expresada biológica y culturalmente. Esta racionalidad establece que lo europeo es lo único legítimo y separa de este modo las formas científicas y no científicas del saber (lo popular, lo "indígena"). La crítica descolonial plantea que no es posible explicar la realidad a partir de lo simple, lo especializado, lo compartimentalizado y lo disciplinario, sino desde una totalidad social (la sociedad mundial y no el Estado-nación) y desde la historicidad, ya que ninguna sociedad es inmutable porque puede ser modificada a partir de la acción social. Esta crítica sostiene, además, que no es posible la objetividad, puesto que quien hace ciencia tiene dentro de sí subjetividades, que no se pueden dejar de lado, y, más bien, hay un compromiso ético por la justicia, la igualdad, la libertad y la democracia.

\section{Elementos para una caracterización no eurocéntrica de la crisis actual}

En este apartado desplegamos algunas ideas sobre la crisis actual que pueden ayudar a ubicar mejor las prácticas y luchas por instituir una sociedad alternativa, una solidaria. Se discute el contexto en el que surge y se potencia lo que denominamos "solidaridad económica”, y por qué la lucha por la solidaridad debe situarse en una disputa más amplia que la del ámbito de la economía, para abarcar el conjunto de las relaciones de poder capitalistas con su imaginario del progreso-desarrollo y el proyecto de la modernidad.

8 Respecto de la crítica al eurocentrismo, ver Wallerstein (1996), Germaná (2002) y Marañón (2012a). 


\section{¿Crisis civilizatoria”?}

Para sintetizar la convergencia de los diversos e irresolubles problemas existentes (destrucción ambiental, desempleo y pobreza crecientes, concentración del poder), es recurrente el término de crisis civilizatoria. No obstante, este término es cuestionable porque implica que hay una crisis, no de la civilización occidental, sino del total de la civilización; empero, esto no es cierto, pues el concepto "civilización" es un constructo que fue creado como parte de la mirada racista europea para justificar la dominación y explotación de los no europeos o de los no blancos desde el siglo XVI. Esto servía para justificar, por tanto, la CP, al establecer que los no europeos eran (y siguen siendo) inferiores cultural y biológicamente (Quijano, 2002). Por tal razón, es más apropiado referirse a la crisis de lo que Wallerstein (1988) denomina "sistema histórico" o Quijano (2001, 2002, 2007a), un patrón de poder específico, estructurado hace más de cinco siglos: se trata del patrón de poder colonial, moderno, capitalista, mundial y eurocentrado, el cual sigue dominando nuestras vidas.

\section{Desempleo estructural, financiarización e hipertecnocratización de la racionalidad instrumental ${ }^{9}$}

El actual patrón de poder atraviesa una mutación profunda, traducida en el alejamiento definitivo de las promesas de la modernidad, entre estas, la libertad, la igualdad, la solidaridad y la democracia. Tres tendencias ilustran esta mutación: los procesos de desempleo estructural, la financiarización estructural y la creciente tecnocratización de la racionalidad instrumental.

El desempleo estructural es el volumen de trabajadores que no puede ser asalariado de modo permanente ni siquiera en la fase ascendente del ciclo económico capitalista. Esta situación se explica por la creciente sustitución de trabajo vivo por trabajo acumulado en los procesos productivos y por la solución del capital a la crisis de rentabilidad que enfrentaba en los setenta del siglo pasado, lo que destruyó las conquistas laborales, impulsó formas no reguladas de asalariamiento, con la finalidad de reducir costos, y originó una reexpansión de la extracción del plusvalor mediante la plusvalía absoluta. El desempleo

\footnotetext{
9 Sobre estos aspectos, veánse Quijano (2011), Marañón y
} López (2013), Marañón (2014a y 2014b). estructural significa el crecimiento del volumen de fuerza de trabajo excedente por encima del ejército industrial de reserva y su consecuencia es la marginalización creciente, en la idea del "polo marginal", desarrollada por Quijano (2014b).

La financiarización es la transformación estructural de la relación entre la esfera de la producción y de la circulación, entre el capital productivo y financiero, o entre las fuentes de ganancia e inversión productiva y financiera, siempre en favor de estas últimas. El crecimiento desmesurado, a la vez que autónomo, del capital especulativo compromete seriamente y pone en riesgo la unicidad del proceso de reproducción del sistema al introducir un factor de disrupción sistémica, que tiende a provocar la implosión de la lógica global - e incluso una ruptura con esta-, que es recogida por la fórmula general del capital: D-M-D' (Romero, 2010).

Finalmente, la hipertecnocratización de la racionalidad instrumental se refiere a la capacidad del capital de hallar soluciones (técnico-científicas) cada vez más eficaces por encima de consideraciones ecológicas, ideológicas, éticas y políticas, y esto deja atrás las promesas de libertad, igualdad y solidaridad, que habían caracterizado el proyecto moderno en términos económicos. Según Sánchez (2007), la hipertecnocratización en la actual etapa de financiarización estructural del capital se traduce en que la concentración y acumulación de riqueza no tienen un objeto. Mientras que para el capital productivo las ganancias bajo la forma de plusvalía están limitadas por las condiciones de explotación de la fuerza de trabajo, para el capital financiero los beneficios bajo la forma de tasas de interés, de valor del dinero, no tienen límite.

Las tres tendencias anteriores nos muestran que el capitalismo industrial ha cedido su lugar al capitalismo financiero, lo que ha originado y expandido el desempleo estructural, de modo que ya no hay posibilidades de vivir a través del trabajo asalariado, el mismo que es solo un tipo de trabajo, aunque haya sido impuesto como el "trabajo legítimo" por el capitalismo. El capitalismo financiero es la expresión de una correlación de fuerzas muy favorable al capital frente al trabajo, pues le ha impuesto a este una relación sin derechos laborales ni sociales, sin ciudadanía, con el objetivo de reconcentrar sin límites la riqueza. El capitalismo financiero significa, además, un alejamiento definitivo de las promesas primigenias de la modernidad, pues se origina una racionalidad instrumental hipertecnocratizada, a la cual no le interesa sino acumular poder y riqueza. Finalmente, 
el desempleo estructural permite sentir y pensar en las posibilidades que se abren para las formas no mercantiles y solidarias tanto de trabajo como de vida.

\section{Del Estado-nación al bloque imperial mundial y al vaciamiento de la democracia $^{10}$}

La globalización del patrón de poder capitalista ha erosionado al Estado-nación ${ }^{11}$, hasta hace poco la institución pública central del poder en el mundo del capitalismo, para dar paso a la conformación de un bloque imperial mundial, integrado por algunos modernos estados-nación - el grupo de los siete (además de Rusia) - . Este bloque se caracteriza por que sus decisiones son impuestas sobre el conjunto de los demás países y sobre los centros neurálgicos de las relaciones económicas, políticas y culturales del mundo; actúa sin representatividad, ya que no ha sido elegido o designado por los demás estados del mundo, y es una autoridad pública mundial, aunque no un efectivo estado mundial. Así mismo, este bloque no está constituido solo por los estados-nación mundialmente hegemónicos, sino incluye también entidades intergubernamentales de control y ejercicio de la violencia (OTAN); a entidades intergubernamentales y privadas de control del flujo mundial de capital, financiero (Fondo Monetario Internacional, Banco Mundial, Club de París, Banco Interamericano de Desarrollo, entre las principales) y de control de intercambios comerciales (OMC, OCDE), y a las grandes corporaciones globales. Por último, este bloque es una suerte de gobierno mundial invisible que muestra la reconcentración mundial del control de la autoridad pública, a escala global (Quijano, 2001).

La globalización del patrón de poder implica una internacionalización del Estado y de su dependencia respecto a los flujos internacionales de capital y las estrategias de las corporaciones multinacionales; las políticas macroeconómicas se perfilan hacia el lado de la oferta para favorecer la acumulación de capital, lo que restringe las posibilidades de intervención en el campo de la política social. También implica que hay una la privatización de la política, pues si los estados se desempeñan como mediadores y coordinadores entre intereses de empresas transnacionales,

\footnotetext{
10 Al respecto ver Marañón (2014b), Quijano (2001).

11 Un análisis histórico de la conformación y crisis del Estado-Nación puede verse en De Rivero (1998).
}

los procesos de decisión política son transferidos a un sistema de negociación "oscuro" tanto en el ámbito nacional como en el internacional. Por otro lado, la globalización provoca una pérdida de autonomía de los estado-naciones y un vaciamiento de la democracia liberal, al originar un debilitamiento estructural de las instituciones y procesos democráticos, ya que estos formalmente siguen funcionando pero su contenido se erosiona pues las decisiones políticas centrales se toman por fuera. Por consiguiente, el capitalismo financiero se caracteriza por una crisis de representación estructural (Hirsch, s. f.; 2006): se debilita el Estado-nación, pero no el Estado en general, lo cual significa que el modelo de Estado actual tiene más semejanza con el del liberalismo de hace dos siglos que con el Estado democrático del siglo xx (Lander, 1998).

La conformación del bloque mundial de poder significa, pues, la erosión de la soberanía del Estadonación y de la democracia representativa, pues ambas instituciones responden cada vez más y de un modo vertical a las necesidades de un entramado de interés internacionales y nacionales que a los del conjunto de la población del país. Esta situación invita a reflexionar sobre si el Estado es la única forma de vivir en sociedad o si hay posibilidades de constituir una autoridad colectiva horizontal a través de la democracia directa.

\section{Crisis del "progreso-desarrollo"12}

Según Nisbet (1986), la idea de progreso se ha referido desde los griegos al avance del conocimiento práctico contenido en las artes y las ciencias, y, en el mundo moderno, se refiere a la esperanza en un futuro de libertad, igualdad y justicia individuales en una línea de crecimiento acumulativo y continuo, para desarrollar las potencialidades humanas. Para Bacon, el fin del conocimiento era instrumental, pues la investigación de la naturaleza no se orientaba a la satisfacción especulativa, como pensaban los griegos, sino al dominio humano sobre la naturaleza (Bury, 1971, pp. 55-63). Descartes planteó la supremacía de la razón y la invariabilidad de las leyes de la naturaleza, estableciendo una declaración de la independencia del hombre, pues tanto su teoría mecánica del mundo como su doctrina de la inmutabilidad de la ley natural excluían la doctrina de la providencia (Bury, 1971, pp.

12 Sobre estos aspectos, veánse Marañón (2015a y 2014a), Quijano (2000), Acosta (2014), Gudynas (2011). 
66-78). Condorcet (1743-1794) desarrolló una visión evolucionista del espíritu humano, según la cual hay nueve etapas en la historia, con una décima aún por venir, que sería cuando el hombre conocería todos los gozos de la libertad, la igualdad, la justicia y el humanitarismo. Para Condorcet había leyes invariables en el desarrollo surgidas de la propia naturaleza humana, las cuales, cuando finalmente fueran descubiertas por la ciencia, guiarían nuestra visión del futuro hacia la desaparición no solo de la miseria y el hambre, sino también de todas las restantes coerciones impuestas a la mente humana (Nisbet, 1986, pp. 15-16). Condorcet, como ningún otro, señaló el desplazamiento de la edad de oro de la humanidad, trasladándola del pasado hacia el futuro, a partir del conocimiento racional (Carr, 1985, p. 29).

La visión dominante sobre el progreso no era neutra, no se refería a la humanidad en su conjunto . Tal visión tenía a la colonialidad como telón de fondo, ya que la sociedad de referencia era la civilización europea, blanca, y se trataba de expandir sus logros al resto del mundo, uno "atrasado" y "salvaje", a través de prácticas coloniales e imperialistas. Esta idea fue reformulada bajo el concepto de desarrollo a inicios del siglo xx y, en especial, a partir de la década de 1940. Según Escobar (2012), Harry Truman presentó en 1949 la idea del desarrollo, directamente vinculada a la de subdesarrollo; esta estaba definida con base en el ingreso per cápita de cada país: unos países habían avanzado en la ruta del progreso y otros estaban atrasados, por lo que América Latina y otras regiones del sur debían aplicar un conjunto de políticas, instrumentos e indicadores para salir del "subdesarrollo" y llegar a la deseada condición del "desarrollo".

Quijano (2000) sostiene que la aspiración al desarrollo se universalizó convirtiéndose en la práctica en una idea-fuerza, en aspiraciones motivadoras e impulsoras de movimientos y cambios mayores en la sociedad. En el debate sobre el desarrollo y el subdesarrollo destacó un supuesto dominante: que el desarrollo es una cuestión referida a países o regiones, y no una asociada a un patrón de poder específico. Este supuesto mostraba un desplazamiento que se presentó en la perspectiva de conocimiento sobre la sociedad, en la cual se pasó de la perspectiva mundial a la del Estado-nación; este último pasó a ser no solo una unidad de análisis, sino el enfoque mismo, una manera de percibir y estudiar los problemas, de modo que las preguntas centrales se orientaban a identificar los "obstáculos al desarrollo" y las formas de enfrentarlos. En América Latina, los enfoques más difundidos fueron la teoría de la modernización, impulsada principalmente por Estados Unidos y estaba asociada con el estructural-funcionalismo; la otra fue la teoría del imperialismo capitalista, vinculada, principalmente, al materialismo histórico.

La primera logró imponer una visión eurocéntrica y fragmentaria de la sociedad en áreas específicas: economía, sociedad, cultura y política; a su vez, estableció que la cultura explicaba las diferencias en el desarrollo de diferentes sociedades. Esto se refería a la racionalidad y a la ideología, especialmente, religiosa. Los "desarrollados" eran los "modernos", los "racionales" y los "protestantes", mientras que los "subdesarrollados" eran los "tradicionales", los no protestantes, que tenían una racionalidad premoderna, sino francamente "primitiva". Algunos de los rasgos específicos de la moderna sociedad capitalista en los países "centrales" fueron propuestos como expresiones básicas de la modernidad y como el marco histórico insustituible del desarrollo económico: el principio de ganancia, el valor del dinero y del mercado, la idea de que el sentido de la vida es el trabajo y el consumo, el universalismo de la respectiva orientación valórico-normativa. Estas eran características de la modernidad, de la "racionalidad", y se encontraban más en los pueblos protestantes que en los que no lo eran. Los rasgos opuestos eran, pues, parte de la tradición y eran los "obstáculos" que se debían remover en el camino del desarrollo. El desarrollo era, ante todo, modernización. Puesto que en la teoría de la modernización no se intentó explicar por qué unos grupos tenían una cultura en lugar de la otra, esa categoría de "cultura" aparece más bien como un modo de referirse a las diferencias "naturales" entre los "desarrollados" y los "subdesarrollados".

Distanciándose de la postura eurocéntrica que privilegia al Estado como unidad de análisis, Wallerstein (1998, pp. 117-124) sostiene que el Desarrollo no es el desarrollo de un país, de un Estado sino se trata de un patrón de poder o una sociedad mundiales. Quijano (2011) añade que se trata de la sociedad capitalista mundial la que no es homogénea en todo el espacio mundial, pues articula múltiples espacio-tiempos o contextos, que son histórica y estructuralmente desiguales y heterogéneos. Por lo tanto, este patrón de poder, si bien es mundial, se desarrolla de modos diferentes y en niveles distintos en diferentes espacio-tiempos o contextos históricos (Quijano, 2011). Esto hace indispensable preguntarse cuáles son los factores históricos que explican la diferentes trayectorias del desarrollo del 
patrón de poder capitalista entre regiones y países, y si es todavía realista para los latinoamericanos estar tentados por el desarrollo capitalista. Respecto a la primera pregunta es posible sostener que la sociedad capitalista es más desarrollada en los países donde el moderno Estado-nación es más democrático, más nacional y más fuerte (Quijano, 2011). Con relación a la segunda cuestión, es evidente que el desarrollo es esquivo para los países latinoamericanos, y que las diferencias sociales entre países y dentro de los países se han ampliado (Wolfe, 1976; De Rivero, 1998; Unceta, 2014). Las instituciones básicas del imaginario del desarrollo se encuentran en procesos de crisis irreversibles, dentro de los cuales se encuentra el Estado, la democracia representativa, los partidos políticos, el trabajo asalariado, la "naturaleza", el patriarcalismo y la subjetividad basada en el conocimiento científico (en el eurocentrismo), así como la propia idea de "raza".

Así, el imaginario de progreso-desarrollo no es neutro ni universal, sino que es producido desde el patrón de poder e impuesto a los dominados, de modo que estos aspiran a imitar las pautas de vida y de felicidad de los dominadores, copiando sus instituciones, valores y normas. La situación crítica del imaginario de progreso-desarrollo invita a buscar alternativas con base en nuestra propia realidad latinoamericana.

\section{Crisis de la modernidad}

Al contrario de la visión eurocéntrica que sostiene la modernidad fue producida endógenamente desde Europa, según Quijano, la modernidad fue una intersubjetividad coproducida a partir del siglo XVI por lo que luego serían Europa y América Latina (Quijano, 1988a; 1998a; 2001); esta proponía un modo de existencia racional basado en la autonomía individual, la igualdad, la libertad y la democracia. Se trataba de construir una sociedad racional, entre iguales, en la cual el poder estuviera dentro y no fuera de la sociedad. La modernidad perseguía la desacralización de la autoridad en relación con el conocimiento y las jerarquías sociales, hecho que implicó la primacía de la racionalidad humana, además de la legitimación del individualismo -humanos con foro propio, libres-y de la igualdad social. Se admitía que la sociedad es producida por la acción humana y que no es inmutable, lo que llevaba la mirada histórica del pasado al futuro como el tiempo de la realización de las utopías.
La modernidad emerge en el mismo movimiento histórico de constitución del capitalismo, de modo que la vinculación entre modernidad y capitalismo se desarrolla en el marco de mercados masivos en rápida expansión, en los cuales las viejas jerarquías sociales y sus mecanismos de control tanto mental como social se hacen sentir como obstáculos que deben ser eliminados. Así, en Europa, el imperio, la monarquía absoluta y la Iglesia son instituciones que deben ser destruidas, o modificadas, para dar paso al Estado-nación, a la república y a la universidad laica.

Desde la Ilustración, la Revolución francesa y la Revolución de Estados Unidos, la modernidad presenta una disputa entre dos proyectos distintos y opuestos, a saber, el del capital y el del trabajo, articulados en el patrón eurocéntrico de poder de modo diferenciado: por un lado, el individualismo y la razón instrumental, y, por el otro, la igualdad social y la razón histórica (Quijano, 1988a; 2001). El primer elemento supone la racionalidad instrumental y el segundo, la racionalidad histórica, pues no se ocupa solo de definir los mejores medios para alcanzar los fines, también cuestiona los fines y la trayectoria de las acciones y su relación con los medios, los instrumentos y los recursos para actuar. La racionalidad presupone individuos, no solo libres (con foro propio), sino socialmente iguales, es decir, con un lugar igual en las relaciones sociales, en las relaciones de poder. Ambas racionalidades han coexistido de manera contradictoria, pues se busca la igualdad social, pero está articulada a la idea de raza, que es la fuente básica de desigualdad social. Por esta razón, se plantea que la modernidad es al mismo tiempo colonialidad (Quijano, 1992; 1998a).

Es posible afirmar, por tanto, que la modernidad no equivale ni a la modernización ni al despliegue de la ciencia y la técnica para instrumentalizar la vida humana además de la naturaleza en la perspectiva del capital: individualismo y razón instrumental. La modernidad en su concepción primigenia aludía a instituir una vida racional basada en la igualdad, la solidaridad, la autonomía y la democracia. Este proyecto se expresó en el ámbito del trabajo en la igualdad social y la razón histórica. La concreción histórica del proyecto de la modernidad se ha alejado definitivamente de sus promesas iniciales, tanto en su vertiente de la razón histórica, aludida en los procesos revolucionarios socialistas del siglo $\mathrm{xx}$, que buscaban la emancipación humana, como en la de la razón instrumental (medios/fines), impulsada por el 
capitalismo y orientada tanto a la dominación como a la explotación (Quijano, 1988) ${ }^{13}$. Se creía que el ejercicio de la razón podía conducir hacia la emancipación humana. No obstante, tenemos consciencia de que la razón, por sí sola, no puede generar todo el conocimiento de la realidad y menos una razón colonial, una razón técnico-instrumental que ha hecho de los seres humanos apéndices de las máquinas, que no reconoce la existencia de los otros, los "no europeos", los "no blancos", que está desgajada del árbol de la vida y que exterioriza a la naturaleza ${ }^{14}$. Respecto a esta última, es preciso enfatizar que la visión dominante la separa de la vida social, además de que la ubica como un objeto que debe ser dominado y explotado para alcanzar el progreso, así como el desarrollo de la humanidad; esto último es realizado según las reglas del mercado, asignándole un precio y privatizando su acceso.

El progreso tiene un ethos antropocéntrico que coloca al humano por fuera de la naturaleza, la que debe ser dominada y manipulada a través del conocimiento científico. Como decía Bacon, que "la ciencia torture a la Naturaleza, como lo hacía el Santo Oficio de la Inquisición con sus reos, para conseguir develar el último de sus secretos" (Acosta, 2011). Carr (1985) argumenta, además, que desde la Revolución Francesa el progreso fue entendido como una abundancia material a partir de la explotación de la naturaleza, elevando el concepto de productividad a un nuevo lugar central dentro de los hechos humanos, de modo que los fisiócratas y Adam Smith establecieron que la riqueza de las naciones no provenía del comercio, sino de la producción; ellos distinguieron entre consumo e inversión y convirtieron a la productividad de toda la sociedad en la preocupación de la economía política (Carr, 1985).

\section{Buen vivir como nuevo horizonte histórico de sentido ${ }^{15}$}

Si los proyectos de la modernidad y del progreso-desarrollo, ambos surgidos como parte del patrón de poder mundial, colonial, moderno, capitalista, están en crisis, es posible sentir y pensar en otro

13 Una discusión sobre las dos vertientes de la Ilustración y de la modernidad puede encontrarse en Fontana (1982).

14 Sobre la crisis de la modernidad, ver Horkheimer y Adorno (2009) y Quijano (1988a), Habermas (1989 y 2002a y 2002b),

15 Al respecto, ver Marañón (2014a y 2015a), Acosta (2011), Gudynas (2011), Walsh (2010 y 2008), Quijano (2011). horizonte histórico de sentido que articule las promesas de la modernidad encarnadas en la razón histórica con las racionalidades "indígenas", para encontrar nuevos equilibrios entre los humanos y con la Madre Tierra. Así, el buen vivir, surgido en América Latina en la década precedente a partir de la resistencia al despojo e irracionalidad del capitalismo, se va perfilando como un nuevo horizonte histórico de sentido, ya que se orienta a tratar de rehacer la vida a partir de la solidaridad humana y con la Madre Tierra en todas las dimensiones de la existencia social: el trabajo, el género, la autoridad colectiva, la subjetividad y la "naturaleza". En esta medida, el buen vivir es una ruptura con el eurocentrismo en la producción de conocimiento. Cuenta con una memoria histórica y un imaginario que se ha cristalizado legalmente en Bolivia y Ecuador, donde se estableció una visión relacional entre humanos y no humanos, y un sentido de pertenencia hacia la "naturaleza" planteando la necesidad de cuidarla. Así, el artículo 71 de la constitución ecuatoriana afirma que "[...] la naturaleza o Pacha Mama, donde se reproduce y realiza la vida, tiene derecho a que se respete integralmente su existencia y el mantenimiento y regeneración de su ciclos vitales, estructura, funciones y procesos evolutivos".

Epistemológicamente, esta postura lleva a abandonar la separación entre el sujeto-objeto que ha fundamentado la acción social de tipo instrumental en la modernidad/colonialidad (Walsh, 2008; Escobar, 2010; Marañón, 2012b). Dávalos (2008) sostiene que la teoría económica vigente se adscribe al paradigma cartesiano del hombre como "amo y señor de la naturaleza", en el cual la naturaleza se comprende como algo externo a la historia humana, lo que posibilita su dominación y explotación; en cambio, el "sumak kawsay" (buen vivir) incorpora la naturaleza en la historia. El buen vivir es, según Gudynas (2011), una crítica al núcleo contemporáneo de la propuesta capitalista del desarrollo en cuanto meta civilizatoria para los países de la periferia. Con el concepto de buen vivir se abandona la comprensión del desarrollo como un proceso lineal; se defiende otra relación con la naturaleza, reconociéndole su condición de sujeto de derechos; no se mercantilizan ni objetivizan las relaciones sociales, ni se reducen todos los bienes a mercancías. Este concepto reconceptualiza la calidad de vida o el bienestar de maneras que no dependen solamente de la posesión de bienes materiales o de los niveles de ingreso, sino principalmente de la satisfacción espiritual. También permite ir más allá de una postura materialista y potenciar la ética, pues 
se trata de otra forma de concebir y asignar valores. Ayuda al avance de la descolonización de los saberes, y se orienta a tomar decisiones democrática. El hecho de identificar valores intrínsecos en lo no humano es uno de los elementos más importantes que diferencia el buen vivir de la modernidad y colonialidad. A partir de esta nueva mirada inmediatamente se redefinen las comunidades, ampliándose a lo no humano y se generan concepciones alternas de la naturaleza.

Recuperar la unidad es uno de los aportes fundamentales del buen vivir, esto es, la complementariedad entre sociedad y naturaleza, estableciendo entre ambas una vínculo relacional y no de exterioridad. Esta es una alternativa que surge de los pueblos de esta región, y es una vía para la subsistencia humana, basada en los conocimientos y prácticas de respeto a la naturaleza por parte de los pueblos originarios. En América Latina se encuentran diversos aportes: el "sumak kawsay" (quechua), en Ecuador; el "suma qamaña" (aymara) y el "nande reko" (guaraní), en Bolivia, y el "lekilaltik" (tojolabal), el "lekil kuxlejal" (tzeltal) y la comunalidad, en México. El buen vivir se constituye, así, como un nuevo horizonte histórico de sentido que expresa la búsqueda de la igualdad respetando la diversidad, por lo que es más pertinente hablar de buenos vivires.

\section{De la "economía solidaria" hacia la solidaridad económica}

Considerando el escenario global de crisis del patrón de poder capitalista y la emergencia del buen vivir, es necesario ubicar a la "economía solidaria" como parte de la reorganización de la sociedad en su conjunto sobre las bases de una racionalidad liberadora y solidaria, que va más allá del capitalismo, del progreso-desarrollo y de la modernidad. Esto requiere distanciarse del eurocentrismo e interrogarse por si la economía solidaria brota de tendencias naturales de la sociedad o si su surgimiento, reproducción y crecimiento están relacionados con factores histórico-estructurales, con las nuevas modalidades de acumulación de capital, con cambios en la dimensión intersubjetiva y, de manera específica, en la forma de producir conocimiento. Desde la CP el surgimiento contemporáneo de la llamada "economía solidaria" se explica como resultado de fuerzas estructurales materiales (la sustitución de trabajo vivo por uno muerto en los procesos productivos). También se tiene que el desinterés del capital financiero, que se manifiesta a partir de los setenta del siglo pasado, en impulsar la construcción de ciudadanía y la integración social , orientándose, por el contrario, al recorte y mercantilización de los derechos sociales básicos y hacia la mercantilización de la Madre Tierra. Asimismo, existe una crisis intersubjetiva, es decir, el creciente rechazo por parte de la población a los fundamentos centrales de la convivencia en el capitalismo (interés individual egoísta, el poder, el dinero, la depredación de la Madre Tierra, el patriarcalismo, el racismo), que se ubica en la crisis del conjunto del patrón de poder colonial, moderno y capitalista.

La economía misma es una construcción de las relaciones de poder, pues no solo implica un sistema de producción, sino también un sistema de poder y de significación (Escobar, 2012, p. 114). Por un lado, la institucionalización del mercado requirió una transformación drástica del individuo, su conversión en un cuerpo dócil, así como la regulación de las poblaciones de manera coherente con los movimientos del capital, con el fin de obligarlos a asistir a las fábricas por medio de un régimen completo de disciplina y normalización. La acumulación de capital requirió establecer una sociedad disciplinaria, en la cual el homo ceconomicus es un sujeto normalizado que produce bajo ciertas condiciones físicas y culturales. Por otro lado, respecto a la significación, un aspecto para considerar es la invención de la economía como un campo autónomo y separado a través de la institución de la economía política como una ciencia de finales del siglo XvinI, la cual se estructuró alrededor de las nociones de producción y trabajo ${ }^{16}$, impuestas como códigos de significación de la vida social en su conjunto.

El pensamiento liberal y eurocéntrico, como una expresión de las relaciones de poder, sostiene que el ser humano es individualista, egoísta y está ávido de acumular ganancias y poder, que toda conducta que se aleje de esta orientación es irracional. Toda acción económica legítima está orientada a tales fines, pues expresa al homo ceconomicus. La institución básica es la empresa capitalista, productora de mercancías y de valores de cambio, caracterizada por su organización vertical, por la separación entre quienes deciden y quienes ejecutan las tareas, por la explotación del trabajo asalariado y de la Madre Tierra. Afirma, además, el pensamiento dominante, que las causas de la pobreza se relacionan, precisamente, con la falta de una conducta racional, individual y egoísta

16 Sobre una crítica a la Colonialidad del "trabajo", ver Marañón (2015b). 
en la población, pues se atribuye a las personas pobres actitudes (ocio, gasto excesivo, resistencia al trabajo disciplinado) y capacidades (bajo nivel de educación) no adecuadas. Desde nuestra perspectiva, se trata de rebatir tal idea proponiendo que la vida social para los sectores sociales dominados y explotados debe tener como fundamento el respeto a los otros seres humanos y el respeto a la Madre Tierra. La forma de concebir la economía como algo homogéneo, orientado por el racionalismo y el utilitarismo, no es un producto natural de la historia y no ha existido desde los orígenes de la humanidad, sino que es el producto de las relaciones de poder que impusieron el capitalismo y un tipo de modernidad, la Modernidad-colonialidad, como modos dominantes de vida.

La crítica descolonial está realizando un esfuerzo por deconstruir la concepción dominante de economía sosteniendo que, a pesar de la importancia de las propuestas recientes para develar la pluralidad económica y cultural, muchas de estas enfrentan dificultades para escapar del economicismo y no confrontan contundentemente la visión dominante de la economía. Sin embargo, las iniciativas inscritas en el horizonte del posdesarrollo "están dirigidas al reconocimiento, la potenciación y el desarrollo de un horizonte plural a favor de la producción, reproducción y desenvolvimiento de la vida, lo que implica privilegiar el biocentrismo como perspectiva analítica, experimental y existencial" (Quijano, 2012, p. 196). Recuperando el aporte de un campesino quechua ecuatoriano, se habla de las "ecosímías", con un sentido positivo, en contraposición a lo negativo de la economía dominante, lo cual alude a múltiples prácticas y visiones económicas, que rescatan iniciativas diversas que resisten, emergen o se reconfiguran, y que, en oposición a la visión económica dominante, conforman un horizonte económico plural: economías solidarias, sociales, del trabajo, comunitarias, andinas y de la reciprocidad; étnicas; de la vida y para; propias, del cuidado, populares, feministas, etc. Se sostiene que:

Tal horizonte muestra la diversidad de comunidades y órdenes culturales que movilizan múltiples maneras de imaginar, edificar, movilizar, apropiar, significar/resignificar la economía y, con ella, la diversidad cognoscitiva con la cual se da cuenta de tal heterogeneidad y, en suma, de la diferencia económico/cultural (Quijano-Valencia, 2012, p. 192).

Si la economía solidaria es un resultado histórico del capitalismo contemporáneo, y la economía no es un ámbito aislado de la vida social, pues influye en otras dimensiones de las relaciones de poder y es influida por estas, ¿por qué llamar "economía solidaria", "otra economía", "outra economía" "economía social", "economía social y solidaria”, "economía popular de solidaridad" a prácticas que si bien tienen un énfasis en lo económico son parte de propuestas de transformación de la sociedad en su conjunto? ¿Por qué no considerar que la economía es un campo específico de las relaciones de poder y por qué separar la dimensión económica de las otras dimensiones del poder en la reflexión sobre las propuestas solidarias? ¿Por qué seguir anclando la propuesta de la economía solidaria dentro del progreso-desarrollo y de la modernidad, proyectos en crisis de carácter irreversible? ${ }^{17}$

Es en tal sentido que proponemos una mudanza conceptual, epistemológica y ontológica, para plantear el concepto de solidaridad económica, tratando de ubicar las prácticas solidarias en el contexto histórico mundial, en la totalidad social y en las relaciones de poder en su conjunto. La solidaridad económica es un momento de las relaciones sociales y de las relaciones de poder que no puede ser separado, en términos eurocéntricos, del conjunto de la vida social; la racionalidad que la sustenta tampoco es exclusivamente económica, sino que permea la integralidad de la vida. En esta orientación, la solidaridad económica comprende el heterogéneo universo de prácticas colectivas encaminadas a la satisfacción de las necesidades básicas, que se basan en racionalidades liberadoras y solidarias, en la reciprocidad, la desmercantilización y el autogobierno, asociadas con un nuevo horizonte de sentido histórico, el buen vivir descolonial. Se trata de unidades económicas populares organizadas colectivamente, con diversas características, como origen, tipo de organización, escala de operación, ámbito de actividad, dotación de recursos y vínculos con los mercados y con el Estado. Tienen como rasgo principal nuevas racionalidades no instrumentales, centradas en relaciones de sujeto-sujeto, y buscan una convivencia equilibrada entre los seres humanos y la Madre Tierra (Marañón, a-en prensa). En términos de las relaciones sociales, están basadas en la

\footnotetext{
17 Sobre la discusión respecto de la "economía solidaria", de la “economía social”, de la "outra economía”, veánse López y Marañón (2010), Marañón (2012b), Marañón y López (2010), López y Marañón (2013), Marañón (2014a y 2014b). Una discusión sobre las propuestas de Coraggio, Singer y Razeto puede verse en Marañón (a-en prensa) y en Marañón y López (2014).
} 
reciprocidad como forma de control del trabajo; en la apropiación no desigual y privada (capitalista) de los excedentes generados; en la igualdad en la comunidad como forma de autoridad colectiva; en el derecho de la Madre Tierra a la existencia y reparación (Marañón y López, 2013); en el diálogo de saberes, y en la igualdad en las relaciones entre géneros. La reciprocidad, entendida como intercambio de trabajo y fuerza de trabajo entre sujetos iguales sin pasar por el mercado, es una relación social total constituida por tres momentos: dar, recibir y devolver, en los cuales las personas están por encima de las cosas y tanto se producen como se reproducen valores como la amistad y la confianza. Es una forma de reconocimiento de las otras personas y de la pertenencia a una comunidad. La cooperación es una manifestación de la reciprocidad, y en las experiencias de solidaridad económica se advierte, por ejemplo, el trabajo colectivo. En muchas de estas organizaciones se entabla además una relación distinta con la naturaleza por ser considerada el origen sagrado de la vida material y social, lo que significa un reencuentro entre sociedad y naturaleza, el retorno de una visión relacional entre ambos y, como se plantea en la perspectiva del buen vivir, que se deje de considerar la naturaleza como un objeto que se puede explotar de forma ilimitada (López, 2014a; 2014b; 2012a; 2012b).

Es muy importante, como afirma Germaná (2016), enfatizar que estas prácticas, denominadas por él "economía de la reciprocidad", son distintas de la ayuda mutua (devolución de la ayuda recibida), de la pobreza (relacionada con un problema de distribución), de la informalidad (vinculada a un problema de condiciones de empleo) y de la marginalidad -fuerza de trabajo desplazada de la producción por la lógica de la acumulación de capital y expresión del "polo marginal del capital”-. También constituyen un patrón específico de organización social, que no se rige por la ley del valor y escapa al control del capital, pues este no puede tenerlo en ninguna de las modalidades del ejército industrial de reserva. La fuerza de trabajo empleada se caracteriza por formar parte de una estructura de supervivencia, pues esta no depende esencialmente de una renta monetaria; sus medios de vida dependen de la capacidad de articular relaciones de intercambio recíproco de bienes o servicios con otros individuos. Son relaciones sociales que no se dan en la institucionalidad política del Estado, sino a partir de un autogobierno, aunque debido al nivel de vida insuficiente, la población implicada en el trabajo de reciprocidad se encuentra expuesta a la manipulación del Estado vía la política asistencialista.

Estas experiencias de solidaridad económica no están por fuera del actual patrón de poder, sino se hacen como resistencia a este; se presentan tensiones entre las racionalidades que expresan: la instrumental dominante y la liberadora y solidaria; en la que predomina esta última. Por ejemplo, las experiencias de solidaridad económica destinan una parte de su producción para la comercialización, incluso en mercados internacionales, pero su participación en estos está orientada a satisfacer necesidades, no para acumular ganancias de manera privada, de modo que la solidaridad y la reciprocidad son más fuertes que las relaciones de mercado (López y Marañón, 2013; Marañón y López, 2010). La solidaridad económica no puede ser separada de la integralidad de la vida ni de las relaciones de poder que estructuran la vida en sociedad. No es posible hablar de "otra economía", "outra economía" u "otras economías" como una práctica restringida a lo "económico", como si bastara (y fuera posible) extender la solidaridad a toda la economía para transitar hacia otra sociedad, solidaria. La lucha por instituir una sociedad alternativa requiere extender la solidaridad a los otros ámbitos de la vida social: la autoridad pública colectiva, la "naturaleza", la relación entre sexos y la subjetividad, pues en cada uno de ellos hay una lucha permanente contra el patrón de poder colonial-moderno, capitalista y eurocentrado.

Se trata de establecer que la economía puede hacerse, y se hace, bajo diversas modalidades organizativas y también puede involucrar esfuerzos separados o integrados de producción, distribución y consumo, con el fin de satisfacer las necesidades humanas en un amplio proceso de desmercantilización del trabajo, de la vida y de la naturaleza (Marañón, 2012b; 2012c; 2014b). Se debe desterrar la idea de que todo lo que existe es un recurso, es decir, algo que puede permitir generar ganancias (el trabajo, la "naturaleza", la vida). Esto significa, al mismo tiempo, rebatir la idea de que la economía es una sola, que tiene como sujeto básico al empresario capitalista y a la empresa capitalista como institución y que se efectúa con el propósito de generar ganancias apropiadas de modo privado. Lo económico solidario, entonces, debe ser impulsado de manera que en cada fase y en cada operación económica una mayor parte del excedente económico sea apropiado por las organizaciones y destinado a una reproducción ampliada de la solidaridad económica. Esto significa que en cada 
transacción económica, por un lado, se debe tender a una mayor presencia de la reciprocidad (intercambio de trabajo y productos del trabajo sin pasar por el mercado) y, por el otro, a avanzar en la apropiación colectiva del excedente en las fases de comercialización y consumo. También se debe proponer un patrón de acumulación que favorezca su expansión y hegemonía (Marañón, 2012b; 2014b).

Es importante debatir sobre la relación entre la solidaridad económica y la autoridad pública colectiva. El impulso de otra economía, enraizada en la reciprocidad y el autogobierno y comunidad, requiere repensar también cuál es el tipo de autoridad pública colectiva que puede favorecer su consolidación y expansión. Esto implica reflexionar sobre si tal autoridad colectiva es el Estado o necesariamente tiene que ser otra de tipo público pero no estatal. Para esto es necesario poner en cuestión la idea de que hay un solo público y un solo privado, es decir, un púbico estatal y un privado. Lo cierto es que el pensamiento dominante ha impuesto la creencia de que la única autoridad pública es el Estado y que lo privado también es único. Pero hay un privado egoísta y mercantil al que corresponde lo público estatal que representa los intereses del privado egoísta y mercantil y también hay otro privado, solidario y colectivo, que no tiene que buscar su expresión pública en el Estado, sino en articulaciones no estatales. Esto es, las acciones e intereses basadas en racionalidades liberadoras y solidarias no tienen que expresarse en el ámbito público estatal, porque el Estado si bien no es monolítico es el garante de las relaciones de dominación y explotación ${ }^{18}$.

\section{Reflexiones finales}

Este artículo propone abrir un debate amplio sobre la solidaridad, la economía, el poder y la vida en este contexto de crisis estructural global capitalista, debido a que se van expandiendo las prácticas solidarias y los estudios realizados, por muy destacados intelectuales, que contribuyen a visibilizarlas, a darles legitimidad teórica, social y política.

No obstante, parece evidente que nuestras apreciaciones teóricas y nuestras prácticas sobre la solidaridad y la economía no han aquilatado de manera profunda tales cambios y que nuestras

18 Sobre esta discusión, veáse Quijano (1998b; 2007b), Marañón (2012a; 2014c; b-en prensa), Coronado (1996) y Zibechi (2006). subjetividades siguen percibiendo y ordenando la realidad desde el imaginario del Eurocentrismo, pues se mantienen fuertes creencias y sentidos comunes respecto del "Estado democrático", de la "democracia representativa", de las "políticas públicas", del "desarrollo" y "subdesarrollo", de la "economía", de la "economía solidaria", "economía outra", de las "economías plurales", de la "naturaleza", de la "ciencia" y la "tecnología", del "mercado", del "trabajo" en cuanto "trabajo asalariado" exclusivamente, de la "eficiencia", del "patriarcalismo", del "evolucionismo" y "dualismo", de la "civilización", de la "modernidad", entre otros.

En otros términos, todavía no hemos advertido de manera suficiente que la lucha por una sociedad alternativa no solo es económica y ética, sino que la crisis estructural actual abarca a toda una forma histórica de convivencia humana, a toda una "civilización", a todo el conjunto del patrón de poder colonial-moderno y capitalista. Esto implica, por tanto, que se trata de un lucha contra la colonialidad del poder, entendida esta como dominación, explotación y conflicto en las cinco áreas básicas de la existencia social: autoridad colectiva, trabajo, naturaleza, género y subjetividad, y que incluye una lucha por el poder, contra la estructura de dominación basada en la "raza" como criterio universal de clasificación social jerárquica; contra el capitalismo o estructura de explotación social que articula varias formas de control del trabajo (reciprocidad, pequeña producción mercantil simple, esclavitud, servidumbre y trabajo asalariado) bajo la hegemonía del capital; contra el eurocentrismo como modo de producción y control del conocimiento; finalmente es necesario luchar contra el imaginario del progreso-desarrollo y contra la propuesta misma de la modernidad, impulsando otro sistema histórico: el buen vivir o los buenos vivires, orientados hacia la descolonialidad del poder.

Es la crisis de un patrón de poder específico, colonial, moderno y capitalista, de sus componentes centrales, del progreso-desarrollo, de la modernidad y del conocimiento científico. Es una crisis que confronta nuestras teorías, creencias, valores, prácticas y que abre la posibilidad de sentir, pensar y actuar de otro modo, lo que impulsa la solidaridad económica como una dimensión de la realidad no separada de la integralidad de la vida, como un espacio de disputa por el poder, desde la igualdad social, la reciprocidad, la desmercantilización, el autogobierno y el diálogo de saberes. 


\section{Referencias}

Acosta, A. (2011). Los derechos de la naturaleza. Una lectura sobre el derecho a la existencia. En A. Acosta y E. Martínez (comp.), La naturaleza con derecho. De la filosofía a la política (pp. 317-368). Quito: Abya-Yala.

Bury, J. (1971). La idea del progreso. Madrid: Alianza.

Carr, E. H. (1985). 1917: antes y después. Madrid: Sarpe.

Coraggio, J. L. (2001). Economía del trabajo: una alternativa racional a la incertidumbre. Seminario Internacional sobre Economía y Espacio (Panel Fronteras de la Teoría Urbana: CGE, Incertidumbre y Economía Popular). Belo Horizonte: Centro de Desarrollo y Planificación (Cedeplar), 6-7 Diciembre, Belo Horizonte, Brasil.

Coraggio, J. L. (2004). Economía del trabajo. En A. Cattani, La otra economía (pp. 151-163). Buenos Aires: Fundación OSDE/Altamira-UNGS.

Coraggio, J. L. (2008). Economía social, acción pública y política. Hay vida después del neoliberalismo (2 ed.). Buenos Aires: Ediciones Ciccus.

Coraggio, J. L. (1 de junio del 2015). Para pensar las nuevas eonomías: conceptos y experiencias en América Latina (pp.71-90). Recuperado el 1 de abril de 2016, de Colóquio Internacional Epistemologias do Sul: aprendizagens globais Sul-Sul, Sul-Norte e Norte-Sul: http:// coraggioeconomia.org/jlc/archivos\%20para\%20descargar/Livro_OE.pdf

Coronado, J. (1996). La estructura de autoridad y representación en una comunidad urbana: La experiencia de la Cuaves 1971-1990. En J. Coronado, y R. Pajuelo (Comp.), Villa El Salvador: Poder y comunidad (pp. 11110). Lima: Cecosam/CEIs.

Dávalos, P. (5 de abril de 2008). Reflexiones sobre el Sumak Kawsay (Buen Vivir) y las teorías del desarrollo. Revista Alai.

De Rivero, O. (1998). El mito del desarrollo: los países inviables en el siglo XXI. Lima: Fondo de Cultura.

De Sousa, B. (2009). Una epistemología del sur. La reinvención del conocimiento y la emancipación social. Ciudad de México: Clacso/Siglo xxI.

Escobar, A. (2010). Una minga para el posdesarrollo. Lima: Programa Democracia y Transformación Global/Universidad Nacional Mayor de San Marcos/Facultad de Ciencias Sociales.

Escobar, A. (2012). La invención del desarrollo. Bogotá: Universidad del Cauca.
Fontana, J. (1982). Historia. Análisis del pasado y proyecto social. Barcelona: Crítica.

Germaná, C. (2002). La racionalidad en las ciencias sociales. Lima: Universidad Nacional Mayor de San Marcos.

Germaná, C. (2014). La colonialidad del poder. Una perspectiva desde el Perú. Revista Diálogo Global, 14(2), 12-13.

Germaná, C (2015). La economía de la reciprocidad y el Buen Vivir. En H. Cottyn, J. Jahancke, L. Montoya, E. Pérez y M. Tempelmann (Comp.), Las luchas sociales por la tierra en América Latina. Un análisis histórico, comparativo y global (pp. 173-182). Lima: Fondo de Investigación de Flandes/Facultad de Ciencias Sociales de la Universidad Mayor de San Marcos/Red Muqui.

Gudynas, E. (febrero de 2011). Buen vivir: Germinando alternativas al desarrollo. Revista Alai, 462. Recuperado de http://www.alainet.org/es/active/48052.

Habermas, J. (1989). El discurso filosófico de la modernidad. Buenos Aires: Taurus.

Habermas, J. (2002a). Teoría de la acción comunicativa (Vol. II). México: Taurus.

Habermas, J. (2002b). Teoría de la acción comunicativa (Vol. I). México: Taurus.

Hirsch, J. (2006). Globalización, capital y Estado. Ciudad de México: UAM-Xochimilco.

Hirsch, J. (s. f.). Alternativas al neoliberalismo ¿de qué tipo $y$ por quiénes? Recuperado el 1 de febrero de 2016 de: http://biblioteca.clacso.edu.ar/ar/libros/mexico/ xochimil/coloquio/Docs/Mesa10/Joachim\%20Hirsch\%202.pdf

Horkheimer, M. y Adorno, T. (2009). Dialéctica de la ilustración. Madrid: Trotta.

Lander, E. (1998). Límites actuales del potencial democratizador de la esfera pública no estatal. En L. C. Bresser Pereira y G. Cunill Grau (Comp.), Lo público no estatal en la reforma del Estado (pp. 447-473). Venezuela: CLAD/Paidós.

Lander, E. (2000). Ciencias sociales: saberes coloniales y eurocéntrico. En E. Lander (Comp.), La colonialidad del saber: eurocentrismo y Ciencias sociales. Buenos Aires: Clacso.

López, D. (2012a). La economía solidaria en Bolivia (tesis de posgrado en Estudios Latinoamericanos). Universidad Autónoma de México, México D.F.

López, D. (2012b). La relevancia de la reciprocidad como relación social primordial en las propuestas de solidari- 
dad económica y de una sociedad alternativa: Algunas reflexiones teóricas. En B. Marañón Pimentel (Comp.), Solidaridad económica y potencialidades de transformación en América Latina. Una perspectiva decolonial (pp. 155-179). Buenos Aires: Clacso.

López, D. (2014a). La reciprocidad como lazo social fundamental entre las personas y con la naturaleza en una propuesta de transformación societal. En B. Marañón-Pimentel (Comp.), Buen vivir y decolonialidad. Crítica al desarrollo y la razón instrumentales (pp. 99120). México: Universidad Autónoma de México.

López, D. (2014b). La reciprocidad en las prácticas de solidaridad económica en México. En B. Marañón (Comp.) Descolonialidad y cambio societal: Experiencias de solidaridad económica en América Latina (pp. 165-202). México: Clacso/Universidad Autónoma de México.

López, D. y Marañón, B (2010). Prácticas económicas populares basadas en la reciprocidad: una discusión teórica desde el pensamiento crítico latinoamericano. Revista Estudios Latinoamericanos, (25), 75-90.

López, D. y Marañón, B. (2013). Racionalidades y prácticas socioproductivas alternativas para el buen vivir. México: Universidad Autónoma de México.

Lugones, M. (2012). Interseccionalidad y feminismo decolonial . En R. Grosfoguel y R. Almanza (Comp.), Lugares descoloniales. Espacios de intervención en las Américas (pp. 119-124). Bogotá: Pontificia Universidad Javeriana.

Pimentel, B. (2012a). La colonialidad del poder y la economía solidaria. Apuntes para la reflexión teórico-metodológica del Grupo de Trabajo Economía Solidaria. En B. Marañón (Comp.), Solidaridad económica y potencialidades de transformación en América Latina. Una perspectiva descolonial (pp. 21-58). Buenos Aires: Clacso.

Marañón, B. (2012b). La economía solidaria en México: Entre las limitaciones conceptuales y la desarticulación práctica. En D. Camacho, A. Lomelí y A. López, $E l$ Campo mexicano sin fronteras. Alternativas y respuestas compartidas (pp. 235-260) (Vol. IV). México: AMER.

Marañón, B. (2012c). Hacia el horizonte alternativo de los discursos y prácticas de resistencias descoloniales. Notas sobre la solidaridad económica en el Buen Vivir. En B. Marañón (Comp.), Solidaridad económica y potencialidades de transformación en América Latina. Una perspectiva descolonial (pp. 125-154). Buenos Aires: Clacso
Marañón, B. (2014a). Crisis global y descolonialidad: La emergencia de una racionalidad liberadora y solidaria En B. Marañón (Coord.), Buen Vivir y descolonialidad. Crítica al desarrollo y la razón instrumentales (pp. 2160). México: Universidad Autónoma de México.

Marañón, B. (2014b). El impulso de la solidaridad económica en América Latina en el contexto de crisis del patrón de poder capitalista, colonial-moderno. Hacia el Buen Vivir y la descolonialidad del poder. Revista de Sociología, (24), 55-82.

Marañón, B. (2014c). La comunidad urbana autogestionaria de Villa El Salvador y transformación societal. Discursos y prácticas seminales de la descolonialidad del poder. En B. Marañón-Pimentel (Coord.) Descolonialidad y cambio societal (pp. 25-94). México, Buenos Aires: Clacso.

Marañón, B. (2015a). El buen vivir: hacia la descolonialidad de la "naturaleza". Encuentro Nacional de Patrimonio Vivo. Escenarios y desafíos de hoy (pp. 100-116). Buenos Aires: Centro Cultural Kirchner.

Marañón, B. (2015b). Crítica del concepto de "trabajo" en la Colonialidad-Modernidad. Ponencia presentada Congreso ALAS, 29 de noviembre-4 de diciembre, San José, Costa Rica.

Marañón, B. (a, en prensa). Notas sobre la Solidaridad Económica y la Descolonialidad del Poder. En B. Marañón (Coord.), Políticas para la solidaridad económica y el buen vivir en México. México: IIEC-UnAm.

Marañón, B. (b, en prensa ). Notas sobre lo "público" y "privado" para la reproducción ampliada de la Solidaridad Económica y del Buen Vivir. En B. Marañón (Coord.), Políticas para la solidaridad económica y el buen vivir en México. México: IIEc-Universidad Autónoma de México.

Marañón, B. y López, D. (2010). Economía solidaria y sociedad alternativa en América Latina. Hacia una agenda de investigación desde la descolonialidad. Alternativ@s,67, Recuperado de http://www.economiasolidaria.org/files/alternativas_67.pdf

Marañón, B. y López, D. (2013). Una propuesta teóricometodológica crítica para el análisis de las experiencias populares colectivas de trabajo e ingresos. Hacia una alternativa societal basada en la reciprocidad . En B. Marañón (Coord.), La economía solidaria en México (pp. 25-58). México: Universidad Autónoma de México. 
Marañón, B. y López, D. (2014). Solidaridad económica, buen vivir y (des)colonialidad del poder. Sociedad $y$ Discurso, (25), 153-178.

Nisbet, R. (octubre de 1986). La idea de progreso. Recuperado de: http://www.eseade.edu.ar/files/Libertas/45_2_ Nisbet.pdf

Quijano-Valencia, O. (2012). EcoSImias. Visiones y prácticas de diferencia económico cultural en contextos de multiplicidad. Popayán: Universidad del Cauca Popayán Colombia.

Quijano, A. (1988a). Modernidad, identidad y utopía en América Latina. Lima: Ediciones Sociedad y Política.

Quijano, A. (1988b). Lo público y lo privado. Un enfoque latinoamericano. En A. Quijano (Comp.), Modernidad, identidad y utopía en América Latina. Lima: Sociedad y Política Ediciones.

Quijano, A. (1992). Colonialidad y modernidad/racionalidad. Perú Indígena, 13 (29), 11-20.

Quijano, A. (1998a). Estado-nación, ciudadanía y democracia: cuestiones abiertas. En H. Gónzalez-Heidulf Schmidt, Democracia para una nueva sociedad (modelo para armar) (pp. 139-154). Caracas: Nueva Sociedad.

Quijano, A. (1998b). La economía popular y sus caminos en América Latina. Lima: Mosca Azul Editores.

Quijano, A. (1992). Colonialidad y modernidad/racionalidad. Perú Indígena, 13 (29), 11-20.

Quijano, A. (2000). El fantasma del desarrollo en América Latina. Revista venezolana de Economía y Ciencias Sociales, 6(2), 73-90

Quijano, A. (2001). Colonialidad del poder, globalización y democracia. En AA.vv., Tendencias básicas de nuestra época (pp. 21-65). Caracas: Instituto Pedro Gual.

Quijano, A. (2002). ¿Entre la"guerra santa” y la cruzada”? Polis, Revista de la Universidad Bolivariana, (3), 1-21.

Quijano, A. (2007a). Colonialidad del poder y clasificación social. En S. Castro-Gómez y R. Grosfoguel, El giro decolonial. Reflexiones para una diversidad epistémica más allá del capitalismo global (pp. 93-126). Bogotá: Pontificia Universidad Javeriana/Instituto Pensar/ Universidad Central-ıısco/Siglo del Hombre

Quijano, A. (2007b). ¿Sistemas alternativos de producción? En J. L. Coraggio, La economía social desde la periferia. Contribuciones latinoamericanas (pp. 145-164). Buenos Aires: UNGs/Altamira.

Quijano, A. (diciembre de 2011). 'Bien vivir': entre el 'desarrollo' y la des/colonialidad del poder (tema central). Revista Ecuador debate, (84), 77-88.
Quijano, A. (2014a). Cuestiones y horizontes: de la dependencia histórico-estructural a la colonialidad/descolonialidad del poder. Buenos Aires: Clacso.

Quijano, A. (2014b). 'Polo marginal' y 'mano de obra marginal'. En A. Quijano, Cuestiones y horizontes: de la dependencia histórico-estructural a la colonialidad/descolonialidad del poder (pp. 125-170). Buenos Aires: Clacso.

Razeto-Migliario, L. (1988). Fundamentos de una teoría comprensiva. Santiago de Chile: Ediciones PET.

Razeto Migliaro, L. (2011). ¿Cómo iniciar la creación de una nueva civilización? Santiago: Ediciones Uvirtual.Net

Razeto Migliaro, L. (2013). Ética y economía. En AA.vv., Desafíos éticos en un mundo complejo. Santiago de Chile: Universitas.

Romero, A. (Mayo-junio del 2010). Elementos fundamentales para la teoría y estrategia de la transición socialista latinoamericana y mundial. Recuperado de: http:// fisyp.codigosur.net/media/uploads/socialat.pdf

Sánchez, J. (Abril del 2007). Desigualdad y nuevas desigualdades: Economía política de un ocultamiento. Revista Ecuador Debate, (70), 149-186.

Singer, P. (2002). Introducao a economia solidaria. Sao Paulo: Perseu Abramo.

Singer, P. (2007). Economía solidaria. Un modo de producción y distribución. En J. L. Coraggio, La economía social desde la periferia. Contribuciones latinoamericanas (pp. 59-78). Buenos Aires: ungs/Altamira.

Singer, P. (Enero de 2009). Relaciones entre sociedad y Estado en la economía solidaria. Íconos. Revista de Ciencias Sociales, (33), 51-65.

Unceta, K. (2014). Desmercantilización, economía solidaria y buen vivir: Propuestas desde el postcrecimiento. En A. Acosta y E. Martínez, Desarrollo, postcrecimiento y buen vivir: Debates e interrogantes. Quito: Abya-Yala.

Wallerstein, I. (1988). El capitalismo histórico. México: Siglo XXI.

Wallerstein, I. (1996). Abrir las ciencias sociales. México: Siglo XXI.

Wallerstein, I. (1998). Impensar las ciencias sociales. México: Siglo XXI.

Walsh, C. (2008). El interculturalizar de la nueva Constitución ecuatoriana. Encuentros y desencuentros con la Carta boliviana. Revista Cuatro Intermedio, (88), 1-7

Walsh, C. (2010). Development as Buen Vivir: Institutional arrangements and (de)colonial entanglements. Development, 53(1), 15-21. http://dx.doi.org/10.1057/ dev.2009.93 
Wolfe, M. (1976). El desarrollo esquivo. Exploraciones en la política social y la realidad sociopolítica. Buenos Aires: FCE/Cepal.

Zibechi, R. (2006). Dispersar el poder. Los movimientos como poderes antiestatales. México: Taller Editorial La Casa del Mago. 